\title{
SISTEM PAKAR UNTUK DIAGNOSA PENYAKIT MATA PADA MANUSIA
}

\author{
Efani Desi ${ }^{1}$ \\ Fithry Mayasari² \\ Fitriana Harahap ${ }^{3}$ \\ e-mail:fannie.feehily@yahoo.com,maya_han88@yahoo.co.id, \\ f3anahrp@gmail.com
}

Diterima : 8 Maret 2011/Disetujui : 22 Maret 2011

\begin{abstract}
Eyes are very important senses in human life to see. If eyes disorders or diseases of the eye, it will have fatal consequences for human life. So it should be eye is a member of the body that needs to be maintained in daily health. Expert system is a method of science artificial intelligence to be an application program diagnosis of eye diseases in humans are computerized as well as seek to replace and mimic the reasoning process of an expert or experts in solving the problem specification that can be said to be a duplicate of an expert because the knowledge of science is stored in a database system. Expert System For Diagnosis of Eye Disease In Humans use forward chaining method aims to trace the symptoms displayed in the form of questions to diagnose the type of illness with a software-based desktop management system. Expert system software can recognize the type of eye disease after the consultation by answering a few questions that displayed by the application of expert systems and can infer some kind of eye disease in the suffering by the patient. Data diseases that are recognized to adjust the rules (rules) are made to match the symptoms of eye diseases and give a percentage value to determine the value type approach a patient's disease.
\end{abstract}

Keywords: Expert System, Forward Chaining, Diagnosis, Eye, Man.

1. Dosen Jurusan Teknik Informatika, STMIK Potensi Utama

Jl. K.L. Yos Sudarso Km. 6,5 No. 3 A Tj. Mulia, Medan, Telp (061) 6640525

2. Dosen Jurusan Teknik Informatika, STMIK Potensi Utama

Jl. K.L. Yos Sudarso Km. 6,5 No. 3 A Tj. Mulia, Medan, Telp (061) 6640525

3. Dosen Jurusan Teknik Informatika, STMIK Potensi Utama

Jl. K.L. Yos Sudarso Km. 6,5 No. 3 A Tj. Mulia, Medan, Telp (061) 6640525 


\section{ABSTRAKSI}

Mata merupakan suatu panca indra yang sangat penting dalam kehidupan manusia untuk melihat. Jika mata mengalami gangguan atau penyakit mata, maka akan berakibat sangat fatal bagi kehidupan manusia. Jadi sudah mestinya mata merupakan anggota tubuh yang perlu dijaga dalam kesehatan sehari-hari. Sistem pakar merupakan suatu bagian metode ilmu-ilmu artificial intelligence untuk dibuat suatu program aplikasi diagnosa penyakit mata pada manusia yang terkomputerisasi serta berusaha menggantikan dan menirukan proses penalaran dari seorang ahlinya atau pakar dalam memecahkan masalah spesifikasi yang dapat dikatakan duplikat dari seorang pakar karena pengetahuan ilmu tersebut tersimpan di dalam suatu sistem database. Sistem Pakar Untuk Diagnosa Penyakit Mata Pada Manusia menggunakan metode forward chaining bertujuan menelusuri gejala yang ditampilkan dalam bentuk pertanyaan-pertanyaan agar dapat mendiagnosa jenis penyakit dengan perangkat lunak berbasis dekstop management system. Perangkat lunak sistem pakar dapat mengenali jenis penyakit mata setelah melakukan konsultasi dengan menjawab beberapa pertanyaan-pertanyaan yang ditampilkan oleh aplikasi sistem pakar serta dapat menyimpulkan beberapa jenis penyakit mata yang di derita oleh pasien. Data penyakit yang dikenali menyesuaikan rules (aturan) yang dibuat untuk dapat mencocokkan gejala-gejala penyakit mata dan memberi nilai persentase agar mengetahui nilai pendekatan jenis penyakit pasien.

Kata Kunci : Sistem Pakar, Forward Chaining, Diagnosa, Mata, Manusia.

\section{PENDAHULUAN}

Seperti yang diketahui mata adalah suatu panca indra yang sangat penting dalam kehidupan manusia untuk melihat. Dengan mata melihat, menusia dapat menikmati keindahan alam dan berinteraksi dengan lingkungan sekitar dengan baik. Jika mata mengalami gangguan atau penyakit mata, maka akan berakibat sangat fatal bagi kehidupan manusia. Jadi sudah mestinya mata merupakan anggota tubuh yang perlu dijaga dalam kesehatan sehari-hari. Seiring perkembangan teknologi yang sangat pesat, pada bidang kedokteran saat ini juga telah menfaatkan teknologi untuk membantu peningkatan pelayanan yang lebih baik kepada masyarakat luas. Pekerjaan yang sangat sibuk dari seorang dokter mengakibatkan bidang sistem pakar mulai dimanfaatkan untuk membantu seorang pakar/ahli dalam mendiagnosa berbagai macam penyakit, seperti jantung, ginjal, stroke, kanker, gigi, kulit hingga ke mata. 
Sistem pakar merupakan suatu program aplikasi komputerisasi yang berusaha menirukan proses penalaran dari seorang ahlinya dalam memecahkan masalah spesifikasi atau bisa dikatakan merupakan duplikat dari seorang pakar karena pengetahuannya disimpan didalam basis pengetahuan untuk diproses pemecahan masalah. Data yang tersimpan dalam database akan menginformasikan suatu keluhan pasien dengan akurat dan dapat menyimpulkan jenis penyakit mata yang diderita oleh pasien.

\section{PERMASALAHAN}

Beradasarakan uraian diatas, maka perumusan masalah pada penelitian dapat adalah bagaimana suatu sistem pakar dapat mendiagnosa jenis penyakit mata manusia menggunakan metode forward chaining.

\section{Tujuan dan Manfaat Penelitian}

Membuat suatu perangkat lunak untuk dapat diagnosa penyakit mata pada manusia menggunakan rekayasa sistem pakar (expert system). Agar setiap penderita penyakit mata dapat dengan mudah dan cepat mengetahui jenis penyakit mata tanpa harus ke dokter terlebih dahulu. Sistem nantinya untuk menggantikan ahlinya untuk mengenai jenis penyakit dan mencari solusi dalam pengobatannya. Sementara itu, manfaat pembuatan perangkat lunak diagnosa penyakit mata pada manusia menggunakan sistem pakar ini memberikan manfaat untuk:

a. Untuk menghasilkan suatu prototype sistem pakar untuk diagnosa penyakit matadan penerapannya dalam ilmu kedokteran mata.

b. Membantu dokter mengambil keputusan dalam mendiagnosa penyakit mata, sehingga dapat digunakan oleh pengguna yang minimal mempunyai dasar tentang anatomi mata, seperti perawat dan dokter spesialis mata.

\section{HASIL DAN PEMBAHASAN}

\section{Desain Data}

Dari hasil analisis sistem yang dilakukan pada pembuatan perangkat lunak ini, data-data tersebut dikelompokkan sesuai dengan class tertentu untuk memudahkan dalam pembuatan program. Selain itu ada beberapa data yang disimpan pada tabel.

a. Untuk menyimpan data tertentu pada pembuatan perangkat lunak ini dibutuhkan 
empat tabel yaitu :

1. Tabel DbLogin untuk menempatkan data login user setelah melakukan proses registrasi/pendaftaran pasien.

2. Tabel DbPasien untuk menempatkan data-data pasien yang menderita penyakit mata.

b. Pada pembuatan perangkat lunak sistem pakar, dibuat suatu sistem yang dapat menggantikan seorang pakaryang mana sistem menjadi suatu perangkat lunak yang dapat meemberikan kesimpulan konsultasi dari pasien.

\section{Desain Proses}

Pada desain proses akan dijelaskan menggunakan decision tree yang berhubungan dengan tabel dan sering digunakan dalam analisis sistem (sistem non AI). Sebuah decision tree dapat dianggap sebagai suatu semantic network hirarki yang diikat oleh serangkaian aturan (rule). Tree ini mirip dengan pohon keputusan yang digunakan pada teori keputusan. Tree dibentuk oleh simpul (mode) yang mempresentasikan tujuan (goal) dan hubungan (link) yang dapat mempresentasikan keputusan (decision). Akar (root) dari pohon berada disebelah kiri dan daun (leaves) berada di sebalah kanan. Keuntungan utama dari decision tree yaitu tree dapat menyederhanakan proses akuisi pengetahuan.

Tree yang digunakan pada penelitian ini merupakan suatu forward chaining tree. Hal tersebut berkaitan dengan masalah diagnosis yang dibahas dalam penelitian sistem pakar pada diagnosa penyakit mata. Pada forward chaining tree penelusuran informasi dilakukan secara forward (kedepan) seperti yang umumnya digunakan pada masalah-masalah diagnosis lainnya. Dari pernyakit mata yang diketahui, kemudian mencoba melakukan penelusuran ke depan untuk mencari fakta-fakta yang cocok berupa gejala-gejala penyebab penyakit mata yang bersangkutan. Pada tree tersebut dapat dilihat bagaimana suatu gejala penyakit atau kesimpulan gejala penyakit merujuk kepada suatu jenis penyakit tertentu, dan bagaimana beberapa gejala yang sama dapat merujuk kepada beberapa penyakit yang berbeda. Pada penelusuran dengan metode forward chaining dapat dilihat bahwa penelusuran kedepan untuk mengenali penyebab dan jenis penyakit yang dialami oleh pasien. Perhatikan gambar 1 


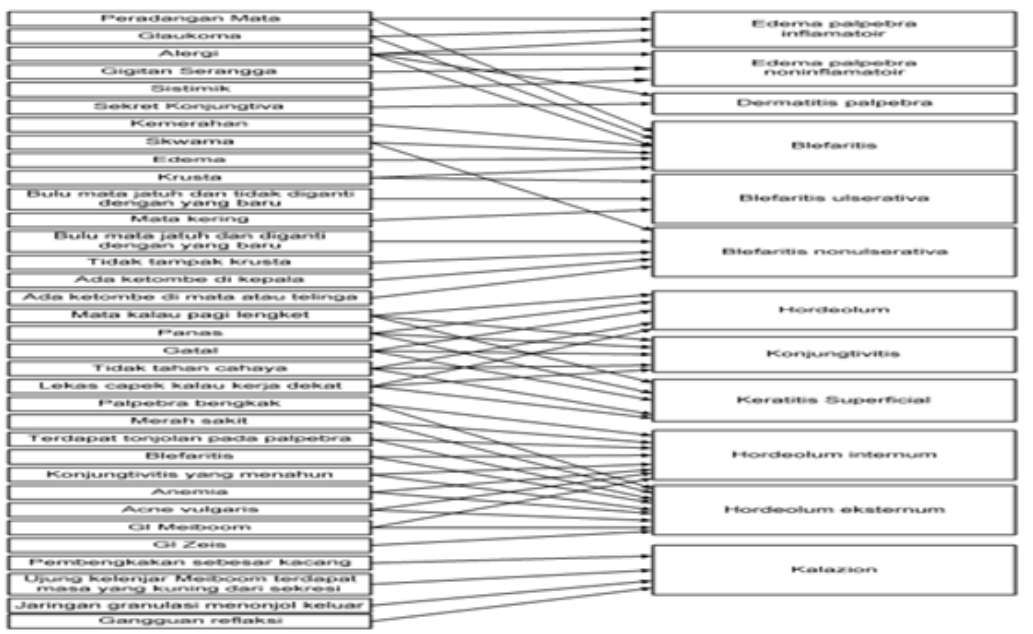

Gambar 1. Decision tree dengan metode Forward Chaining

\section{Design Antarmuka}

Menu utama terdiri dari menu yaitu File Pakar (Login, Pendaftaran Pasien, Ubah data, Logout), Konsultasi, Bantuan Program dan Keluar. Yang mana login, pendaftaran, ubah data logout dan expert system dan kontak admin merupakan sub menu dari masing-masing isi menu yang tampilkan pada menu utama. Menu utama bagian dari indek pada setiap halaman desain antarmuka aplikasi yang akan dikembangkan, perhatikan pada gambar 2 .

\begin{tabular}{|c|c|c|c|}
\hline \multicolumn{3}{|c|}{ Sistem Pakar Diagnosa Penyakit Mata } & \\
\hline File Pakar & Konsultasi & Bantuan Program & 巨回区 \\
\hline $\begin{array}{l}\text { Login } \\
\text { Pendaftaran Pasien } \\
\text { Ubah Data } \\
\text { Logout }\end{array}$ & & $\begin{array}{l}\text { Expert System } \\
\text { Kontak Admin }\end{array}$ & \\
\hline
\end{tabular}

Gambar 2. Desain Antarmuka Menu Utama

\section{Design Diagram Arus Data}

Data flow diagram (DFD) atau diagram arus data merupakan suatu gambaran grafis dari suatu sistem yang menggunakan sejumlah bentuk-bentuk simbol untuk menggambarkan bagaimana data mengalir melalui suatu proses 
yang saling berkaitan. Walaupun nama diagram ini menekankan pada data, situasinya justru sebaliknya: penekanannya ada pada proses.

\section{a. Diagram Konteks}

Diagram konteks bertujuan untuk melihat informasi sistem pakar diagnosa penyakit mata pada proses sistem secara keseluruhan. Dari analisis yang dilakukan, diperoleh diagram konteks seperti gambar 3 .

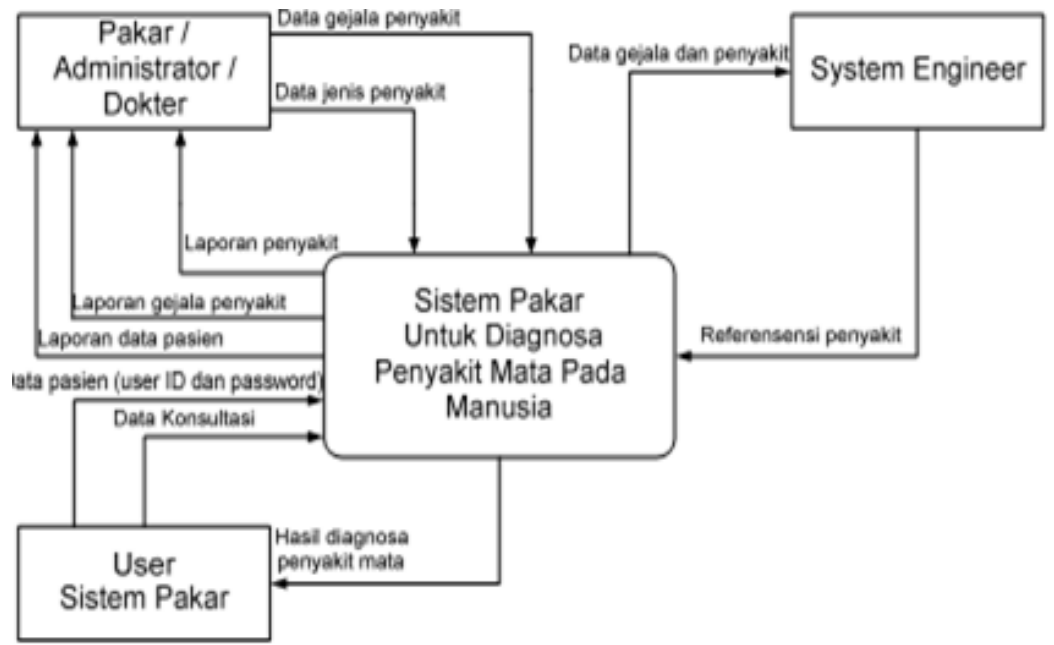

Gambar 3. Diagram konteks

Pada diagram kontek ini terdapat 3 sistem yang mempengaruhi pemprosesan untuk mendiagnosa penyakit mata pada manusia, diantaranya adalah:

1. Pakarnya (dokter/admin sistem) dapat berfungsi sebagai administrator untuk memasukkan data-data baru mengenai gejala dan jenis penyakit.

2. User (pemakai sistem pakar) adalah pasien yang berkonsultasi dengan sistem pakar lunak diagnosa penyakit mata.

3. System Engineer (mesin sistem pakar) untuk mengelolah dan mempresentasikan jenis penyakit dan mengelolah rules (aturan-aturan) gejala menjadi jenis penyakit. 


\section{b. DFD (Data Flow Diagram) Level 1}

DFD level 1 merupakan definisi dari diagram kontek untuk melihat lebih jelas proses sistem yang terjadi pada sistem pakar diagnosa penyakit mata, adapun gambar DFD level 1 dapat dilihat pada gambar 4.

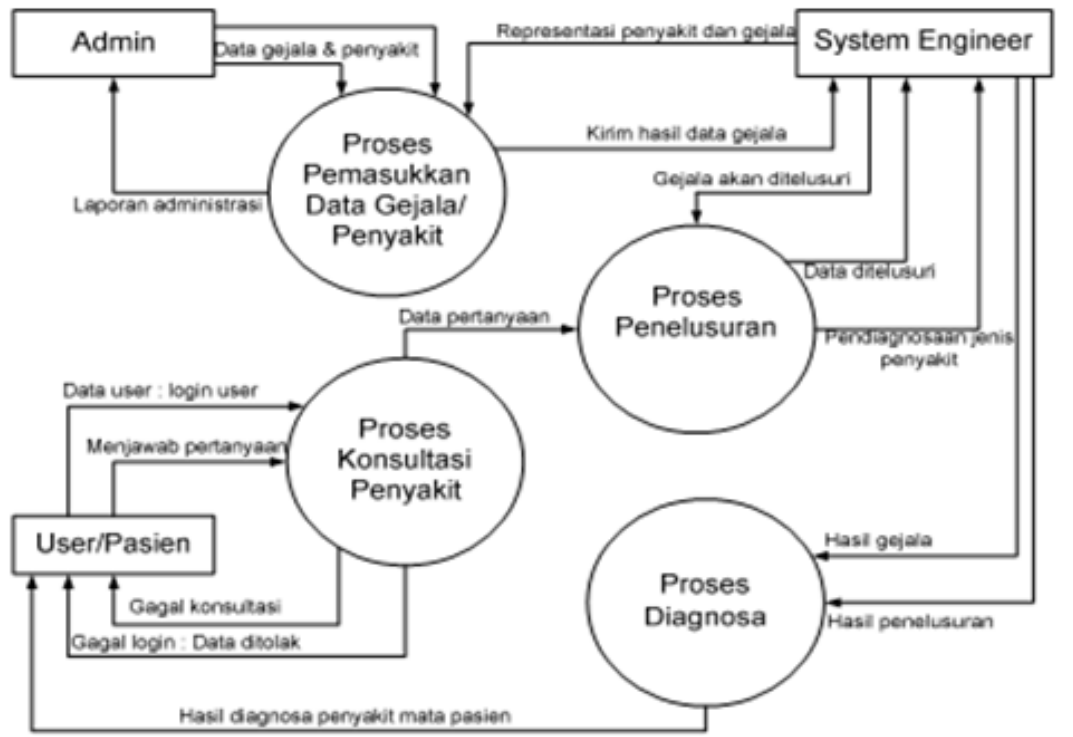

Gambar 4. DFD Level 1

Dapat dilihat bahwa DFD level 1 (satu) memiliki beberapa proses untuk diagnosa mata diantaranya adalah proses pemasukkan data gejala dilakukan oleh admin sistem, kemudian proses konsultasi masuk pada proses penelusuran penyakit dan di diagnosa oleh system engineer, agar menghasilkan suatu kesimpulan maka proses diagnosa mengirim hasil tersebut ke pasien.

\section{Implementasi Sistem}

Implementasi rules dalam sistem pakar pada sub bab ini untuk mengetahui rule-rule atau aturan pada penelusuran sistem pakar untuk mengenali jenis penyakit mata pada manusia. Adapun rules yang dibutuhkan adalah sesuai dengan tabel dan hirarki forward chaining yang telah dibahas pada bab sebelumnya. Rules (aturan-aturan) dalam sistem pakar untuk diagnosa penyakit mata: 


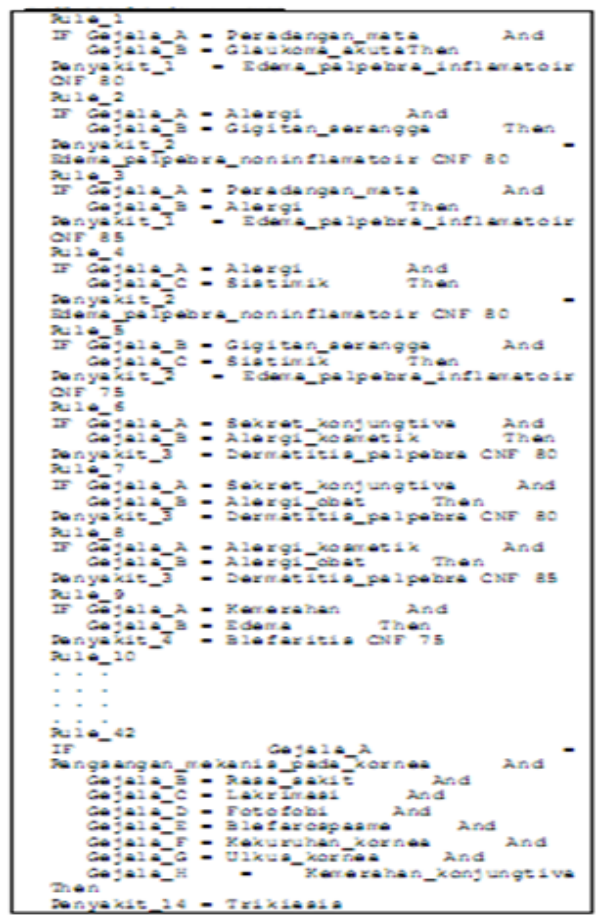

Gambar 5. Impementasi Sistem

\section{Implementasi Antarmuka}

Implementasi antarmuka sesuai dengan desain antarmuka yang telah dibuat pada bab sebelumnya. Perancangan antar muka dapat dilakukan pengujian dengan mencoba menjalankan aplikasi program yang telah dirancang. Seorang pasien dapat saja langsung mencoba melakukan pengujian dengan diawali mendaftar sebagai pasien, kemudian mendapatkan ID (nama penggunaan sistem) dan password. Selanjutnya pasien langsung dapat berkonsultasi dengan perangkat lunak sistem pakar tersebut. Setelah konsultasi, maka sistem akan menghasilkan suatu kesimpulan penyakit pasien.

\section{Menu Utama Aplikasi Sistem Pakar}

Menu utama aplikasi terdiri dari empat menu yaitu, menu File Pakar, Konsultasi, Bantuan Program dan Keluar. Pada menu File Pakar dan Bantuan Program terdapat beberapa sub menu, sub menu yang terdapat pada menu Gambar dan Proses adalah sebagai berikut : 
- Menu File Pakar terdiri dari dua sub menu yaitu jendela Login,Pendaftaran Pasien, Ubah Data, dan Logout.

- Menu Bantuan Program terdiri dari dua sub menu yaitu jendela Expert System dan Kontak Admin.

\section{a. Jendela Aplikasi Login User}

Jendela aplikasi ini digunakan untuk masuk ke dalam sistem pakar sebelum melakukan konsultasi dengan perangkat lunak yang telah dibuat. Pasien (pemakai sistem) dapat menggunakan sistem aplikasi mengisi jendela login user dengan mengisi user id dan password.

\section{b. Jendela Aplikasi Pendataran Pasien}

Sebelum dilakukan login user untuk dapat berkonsultasi, pasien diharapkan mengisi form pendaftaran (registrasi) pasien terlebih dahulu. Agar setiap pasien yang melakukan proses konsultasi terdaftar didalam suatu informasi database. Pasien yang telah terdaftar sebelumnya dapat langsung melakukan pengecekan jenis penyakit dengan sistem pakar pada menu konsultasi.

Pasien yang tidak melakukan proses login user terlebih dahulu tidak dapat melakukan proses konsultasi, kecuali menghubungi secara langsung administrasi sistem pakar untuk didaftarkan sebagai pasien. Adapun penggunaan tombol diatas sebagai berikut:

- Tombol Simpan, dipergunakan untuk menyimpan data yang diisi dan kemudian akan disimpan ke dalam database pada tabelPasien.Pada tombol ini user dapat mengisi data baru setelah mendaftarkan pasien sebelumnya.

- Tombol Batal, dipergunakan untuk membatalkan pengisian pada kolom yang telah diisi.

- Tombol Keluar, dipergunakan untuk keluar atau menutup jendela pendaftaran pada aplikasi sistem pakar dan kembali ke menu utama.

\section{c. Jendela Aplikasi Konsultasi}

Tampilan jendela aplikasi untuk melakukan proses konsultasi, pasien (user) dapat langsung menjawab option Ya atau Tidak dari pertanyaan-pertanyaan yang ditampilkan pada kolom tersebut. Selanjutnya sistem akan dapat menyimpulkan jenis penyakit yang di derita oleh pasien pada kolom Kesimpulan Penyakit Mata. Tombol OK untuk memproses pertanyaan untuk dijawab. Tombol OK, tidak dapat diklik apabila suatu pertanyaan belum dijawab oleh pasien. Sedangkan tombol Keluar adalah untuk keluar atau menutup jendela aplikasi 
konsultasi. Hasil proses diagnosa sistem pakar untuk mengenali jenis penyakit mata yang di derita oleh pasien melalui jendela aplikasi konsultasi yang disebut perangkat

lunak yang dapat menggantikan ahlinya (dokter mata) sebagai pendiagnosa penyakit mata. Adapun hasil penelusuran diagnosa dapat dilihat pada kolom Kesimpulan Penyakit Mata, pada kolom tersebut, menunjukkan bahwa pasien mengalami jenis penyakit mata Edema Palpepbra Inflamatoir memiliki $100 \%$ kemungkinan menunjukkan penyakit tersebut, tetapi dengan hal sama, pasien juga dimungkinkan mengalami penyakit mata lain berjenis Blefaritis, dengan bobot persentase $30 \%$.

\section{Evaluasi sistem}

Untuk mendapatkan data yang akurat, maka dapat dilakukan beberapa uji coba sistem atas jalannya sistem pakar tersebut. Sistem ini diujikan kepada 5 pasien yang menderita penyakit Edema Palpepbra (sesuai dengan hasil diagnosa dokter mata). Dari kelima pasien tersebut menyimpulkan bahwa penyakit yang di derita pasien menunjukkan antara lain, dapat dilihat pada tabel hasil diagnoasa penyakit mata, perhatikan tabel 1 .

Tabel 1. Hasil Diagnosa Sistem Terhadap 5 Pasien Penyakit Mata

\begin{tabular}{|c|c|c|c|c|c|c|}
\hline \multirow[b]{2}{*}{$\begin{array}{c}\text { Jenis } \\
\text { Penyakjit }\end{array}$} & \multicolumn{6}{|c|}{ Pasien Diagnosa } \\
\hline & 1 & 2 & 3 & 4 & 5 & $\begin{array}{c}\% \% \\
\text { Keberhasilan }\end{array}$ \\
\hline Edema & 75 & 65 & 75 & 60 & 65 & 68 \\
\hline Palpepbra & 54 & 46 & 42 & 44 & 40 & 45,2 \\
\hline Blefaritis. & 55 & 50 & 45 & 40 & 45 & 47 \\
\hline Hordeolum & 60 & $45^{\prime \prime}$ & 40 & 55 & 45 & 49 \\
\hline Keratitis & 45 & 60 & 55 & 40 & 45 & 49 \\
\hline 'Superficial' & & & & & & \\
\hline Herpes & & & & & & \\
\hline 'Zoster & & & & & & \\
\hline
\end{tabular}

\section{KESIMPULAN}


Dari hasil uji coba dan evaluasi yang telah dilakukan, maka dapat diambil beberapa kesimpulan sebagai berikut :

1. Metode Sistem Pakar (expert system) yang dibuat dengan proses penelusuran fordward chaining untuk mengenali jenis penyakit mata pada manusia.

2. Cara pemilihan urutan data dengan mengelompokkan jenis penyakit sesuai dengan hasil quisioner dengan beberapa dokter mata.

3. Beberapa gejala penyakit mata dapat menyimpulkan jenis penyakit mata sesuai persentase tertinggi. Semakin tinggi nilai persentase dari hasil penelusuran, maka menunjukkan jenis penyakit mata yang di derita oleh pasien penyakit mata.

4. Pasien dapat langsung berkonsultasi dengan sistem perangkat lunak tanpa harus berkonsultasi dengan seorang pakarnya (dokter mata) dengan syarat harus mendaftarakan diri sebagai pasien dan mendapatkan account login.

5. Hasil diagnosa dapat menampilkan beberapa kemungkinan jenis penyakit mata pada manusia.

6. Sistem hanya dapat mengenali dan mendiagnosa jenis penyakit mata yang ada dalam tabel kebenaran penyakit.

7. Sistem hanya dapat mendiagnosa satu pasien dalam melakukan konsultasi, dan dapat mengulangi kembali konsultasi dengan login sistem.

\section{PUSTAKA}

1. Astuti, Luh Gede., Sistem Pakar Pendiagnosis Kehamilan Entropik, Tesis Ilmu Komputer UGM, Yogyakarta. 2006.

2. Abu-Hakima, S., Halasz, M. \& Phan S., An apporach to hypermedia in diagnostic system, In Intellegent Multi-Media Interfaces, AAAI Press/MIT Press, 1993.

3. Feigenbaum,E.A, \& Buchanan B.G., DENDRAL and Meta-DENDRAL: roots of knowledge systems and expert systems applications. Artificial Intellegence. 1993.

4. Giarratano, C.J. \& Riley D.G., Expert Systems : Principles and programming, fourth edition, THOMSON Course Technology, Canada. 2005.

5. Huge., Medical expert system http://www.privateweb.at/judith/name_3.htm INTERNET tanggal 23 Mei 2007 
6. Jackson, P., Introduction to Expert Systems, third edition, Addison-Wesley, England, UK. 1999.

7. Lalu., Sistem Pakar Diagnosis Penyakit Kulit dan Kelamin, Tesis Ilmu Komputer UGM, Yogyakarta. 2007.

8. McLeod, Raymond.Jr., Management Information System, 6th Ed, Prentice Hall International.Inc, New Jersey. 1995.

9. Neapolitan, R.E., Probabilistic Reasoning in Expert Systems : Theory and Algorithms, Wiley, New York. 1990.

10.Online medical diagnostic expert system. http://easydiagnosis.com/ INTERNET tanggal 14 Mei 2007

11.Paper, Software, and companies. Expert system applications http:// www.pcai.com/web/ai_info/expert_system.html INTERNET tanggal 9 Juli 2007

12.Turban.,E;Jay E.A, Decision Support System and Intellegent System, six edition, Prentice Hall International, Inc. New Jersey. 2001. 